\title{
Developing Neurons Use a Putative Pioneer's Peripheral Arbor to Establish Their Terminal Fields
}

\author{
Wen-Biao Gan and Eduardo R. Macagno \\ Department of Biological Sciences, Columbia University, New York, New York 10027
}

Pioneer neurons are known to guide later developing neurons during the initial phases of axonal outgrowth. To determine whether they are also important in the formation of terminal fields by the follower cells, we studied the role of a putative leech pioneer neuron, the pressure-sensitive $\left(P_{D}\right)$ neuron, in the establishment of other neurons' peripheral arbors. The $P_{D}$ neuron has a major axon that exits from its segmental ganglion to grow along the dorsal-posterior (DP) nerve to the dorsal body wall, where it arborizes extensively mainly in its own segment. It also has two minor axons that project to the two adjacent segments but branch to a lesser degree. We found that the peripheral projections of several later developing neurons, including the AP motor neuron and the $T_{D}$ sensory neuron, followed, with great precision, the major axon and peripheral arbor of the consegmental $P_{D}$ neuron, up to its fourth-order branches. When a $P_{D}$ neuron was ablated before it had grown to the body wall, the AP and $T_{D}$ axons grew normally toward and reached the target area, but then formed terminal arbors that were greatly reduced in size and abnormal in morphology. Further, if the ablation of $a P_{D}$ neuron was accompanied by the induction, in the same segment, of greater outgrowth of the minor axon of $a P_{D}$ neuron from the adjacent segment, the arbors of the same AP neurons grew along these novel $P_{D}$ neuron branches. These results demonstrate that the peripheral arbor of a $P_{D}$ neuron is a both necessary and sufficient template for the formation of normal terminal fields by certain later growing follower neurons.

[Key words: pathfinding, growth cones, development, leech, cell-cell interactions, guidance, axotomy, Hirudo medicinalis]

How do central neurons make precise connections with their peripheral targets? Studies in various systems have suggested that neuronal growth cones use several mechanisms to (1) grow along specific pathways toward their target areas, (2) elaborate branches within those areas, and finally (3) form synaptic connections with particular targets (reviewed in Goodman and

\footnotetext{
Received Aug. 8, 1994; revised Nov. 22, 1994; accepted Nov. 29, 1994

We thank Dr. Laura Wolszon for her critical reading of the manuscript, and Dr. Mu-Ming Poo and Michael Nitabach for useful comments. We also thank Nik Necles for assistance with photographic work. This work was supported by grants from the National Science Foundation and the National Institutes of Health.

Correspondence should be addressed to Eduardo R. Macagno, Columbia University, Department of Biological Sciences, 1003 Fairchild, New York, NY 10027.

Copyright 1995 Society for Neuroscience $0270-6474 / 95 / 153254-09 \$ 05.00 / 0$
}

Shatz, 1993). It is also well known that the earliest developing neurons can act as pioneers in the axonless environment, establishing the framework of major pathways later utilized by other ncurons. Growth concs of the later developing neurons then make specific navigational choices, fasciculating with certain tracts as they extend in the direction of appropriate targets (LoPresti et al., 1973; Bate, 1976; Raper et al., 1983; Goodman et al., 1984; Kuwada, 1986).

The interactions between followers and pioneers are of great interest and have been the subject of many studies in the past 2 decades. So far, studies of the roles of pioneer neurons have focused primarily on examining the initial outgrowth of the later developing neurons in the absence of pioneers. In some systems, when a pioneer neuron is ablated very early in development, its followers fail to find their normal pathways but may, in some cases, reach their target areas through abnormal paths (Macagno, 1978; Raper et al., 1984; Kuwada, 1986; Klose and Bentley, 1989; Ghosh et al., 1990; Pike et al., 1992; McConnell et al., 1994). In other systems, however, later developing neurons are able to find relatively normal paths towards the targets in the absence of pioneers (Keshishian and Bentley, 1983; Eisen et al., 1989; Tix et al., 1989).

During the later phases of axon outgrowth in the target area, both axon-target and axon-axon interactions are known to play important roles (e.g., Ball et al., 1985; Westerfield et al., 1986; Landmesser et al., 1990; Halpern et al., 1991; Sink and Whitington, 1991). However, the role of the pioneer neurons in the formation of the terminal fields of later developing neurons has not been examined in detail, to our knowledge. In this study, we used dye fills, cell ablations, and axon transections to demonstrate that a particular early developing neuron, the $\mathrm{P}_{\mathrm{D}}$ neuron of the leech Hirudo medicinalis, is both necessary and sufficient for the establishment of the terminal arborizations of later developing neurons, but is not required for guiding the initial growth of their axons to the periphery. $P_{D}$ neurons have been shown to pioneer the nerve to the dorsal body wall in another species of leech (Kuwada, 1985).

Some of the results presented here have been published previously in abstract form (Gan et al., 1993).

\section{Materials and Methods}

Hirudo medicinalis embryos were obtained from our laboratory colony and maintained at $23^{\circ} \mathrm{C}$

Cell ablations, cutting the roots, labeling with DiI and DiO, and imaging were carried out exactly as described in the preceding companion article (Gan and Macagno, 1995).

Immunohistochemistry. Embryos, with yolk removed, were fixed in $4 \%$ paraformaldehyde in $0.1 \mathrm{M}$ PBS for $1 \mathrm{hr}$. They were then washed with $1 \%$ Triton-X in PBS three times (20 min each), and incubated overnight at $4^{\circ} \mathrm{C}$ with anti-acetylated- $\alpha$-tubulin monoclonal antibody 


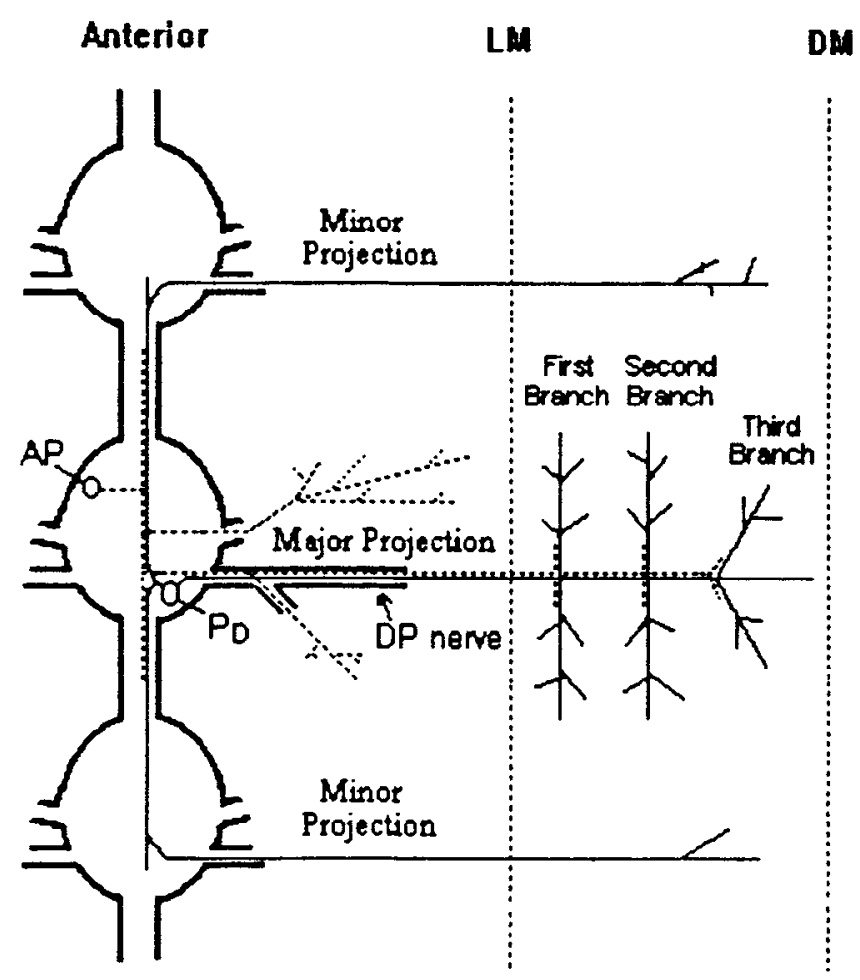

Posterior

Figure 1. Schematic drawing of the $\mathrm{P}_{\mathrm{D}}$ and the AP cell at approximately E10. Three segmental ganglia are illustrated. The CNS is connected to the periphery through two pairs of lateral root nerves, and segmental ganglia are connected to each other via paired connective nerves. The major projection of the AP cell (dotted line) grows to the dorsal germinal plate later than the $\mathrm{P}_{\mathrm{D}}$ cell (solid line). The $\mathrm{P}_{\mathrm{D}}$ cell has branches only in the dorsal region, whereas the AP also has branches in the ventral and lateral germinal plate. Though each cell has a contralateral homolog, only one of each is shown here, for simplicity. $L M$, lateral midline. $D M$, dorsal midline.

(Northwest Immuno-Technology, Eugene, OR) (1:2 in 1\% Triton- $X$ in PBS, with $2 \%$ goat serum). The embryos were then rinsed in $1 \%$ Triton$X$-PBS three times (20 min each) and incubated with peroxidase-conjugated goat anti-mouse secondary antibody (Cappel, Durham, NC) for $2 \mathrm{hr}$ at room temperature (1:50 in 1\% Triton-X-PBS). After washing three times $(20 \mathrm{~min}$ each) with $1 \%$ Triton-X-PBS, the preparations were exposed to $0.1 \%$ diaminobenzidine (DAB, Sigma) and $0.01 \%$ hydrogen peroxide until a brown reaction product appeared. The embryos were then cleared in $100 \%$ glycerol and mounted to image the dorsal posterior nerves.

\section{Results}

The terminal fields of the $P_{D}, A P$, and $T_{D}$ neurons coincide extensively in the dorsal germinal plate

The normal axonal outgrowth of the dorsal pressure-sensitive sensory neuron $\left(\mathrm{P}_{\mathrm{D}}\right)$ in Hirudo medicinalis is described in detail in the preceding companion article (Gan and Macagno, 1995), and is diagrammed in Figure 1. Briefly, at embryonic day 7 (E7) the $P_{D}$ cell sends one major projection into the periphery in its own segment and two oppositely dirceted minor projections into the connective nerves that link adjacent segmental ganglia. The growth cone of the major projection reaches the edge of the germinal plate at E8, slightly earlier than the two minor projections in the adjacent segments. From E8 to E14, the major projection extends six first-order branches from which the second-, third-, and fourth-order branches grow, forming an extensive terminal arbor. In contrast, the minor projections have very few branches during this period.

The peripheral projections of the AP cell (Fig. 1), a motor neuron whose target is as yet unidentified, were found to extend to the contralateral body wall through the two lateral nerve roots, beginning at E9 (Gao and Macagno, 1987). In the body wall, one axon of the AP cell grew along the DP nerve towards the dorsal germinal plate, and two others grew to the ventral and lateral region, one through the anterior nerve, and the other through the ventral posterior nerve. Figure $2 A$ shows double staining at E10 of the AP cell (DiI, in red) and both the dorsal $\left(\mathrm{P}_{\mathrm{D}}\right.$; right territory) and ventral $\left(\mathrm{P}_{\mathrm{V}}\right.$; left territory) $\mathrm{P}$ cells ( $\mathrm{DiO}$, in green; the superpositions of red and green are indicated by yellow). At the light level, it appears that the dorsal posterior axon of the AP cell followed the $\mathrm{P}_{\mathrm{D}}$ cell precisely in order to navigate toward the dorsal germinal plate; this idea was tested directly in the experiments described below. One interesting difference we observed between the growth cones of the AP and the P cells was that those of the AP cell had many fewer filopodia.

Examination of dye-filled AP neurons in E12-13 embryos revealed that the arbor of the AP cell closely resemble that of the $\mathrm{P}_{\mathrm{D}}$ cell, both forming six first-order branches at the same locations (Fig. $2 B$ ). The AP cell appeared to have grown along the same paths as the branches of the $P_{1}$ cell, up to the fourth order, thus forming a terminal field almost congruent with that of the $P_{D}$ cell, although less extensive.

Dorsal $T\left(T_{D}\right)$ cells sent processes into the periphery about 2 $d$ after the $P_{D}$ cells, about the same time as the AP neurons. Their overall morphology was quite similar to that of the $P_{1}$ cells, having one major projection in their own segment and two minor ones in the two adjacent segments. Figure $2 C$ shows double staining of the $T_{D}$ (red) and the $P_{D}$ (green) neurons at E10. Like the AP cells, the $T_{1}$ cell growth cones lacked filopodia and followed the $P_{1}$ cell to the dorsal germinal plate. In E13 embryos, the $T_{D}$ and $P_{D}$, terminal fields were coincident up to the fourth-order branches (not shown).

We also observed that two motor neurons, the AE cells and the NUT cells, both followed the branches of the $P_{1}$ cells faithfully into and within the dorsal germinal plate (not shown). However, this was not true for every cell that grows to the dorsal plate via the DP nerve. For example, in Ell embryos, some axons of the Retzius cell (in red) appeared to follow the $P_{D}$ 's branches, whereas others did not (Fig. 2D).

\section{The $P_{D}$ cell is not required for the formation of the $D P$ nerve}

To determine whether $\mathrm{P}_{\mathrm{D}}$ neurons play a necessary role in the formation of the DP nerve, we ablated single $P_{D}$ cells at E7, just before they sent projections into the periphery. The embryos were then stained at E13 with an antibody against acetylated tubulin, in order to visualize the DP nerve. We found that this nerve was still formed in the segnlent lacking the $\mathrm{P}_{\mathrm{D}}$ cell (Fig. $2 E ; n=29$ of 29). A possible explanation for this finding is that the minor projections from $\mathrm{P}_{1}$, cells in adjacent ganglia might participate in the formation of the DP nerve when the major branch of the local $P_{D}$ cell is absent. To test this idea, the $P_{D}$ cells were ablated in three consecutive ganglia at E7, ensuring that there were no minor projections of neighboring $P_{D}$ neurons in the middle ganglion. When examined $6 \mathrm{~d}$ later, these ganglia still appeared to have normal DP nerves ( $n=14$ of 14 ). 

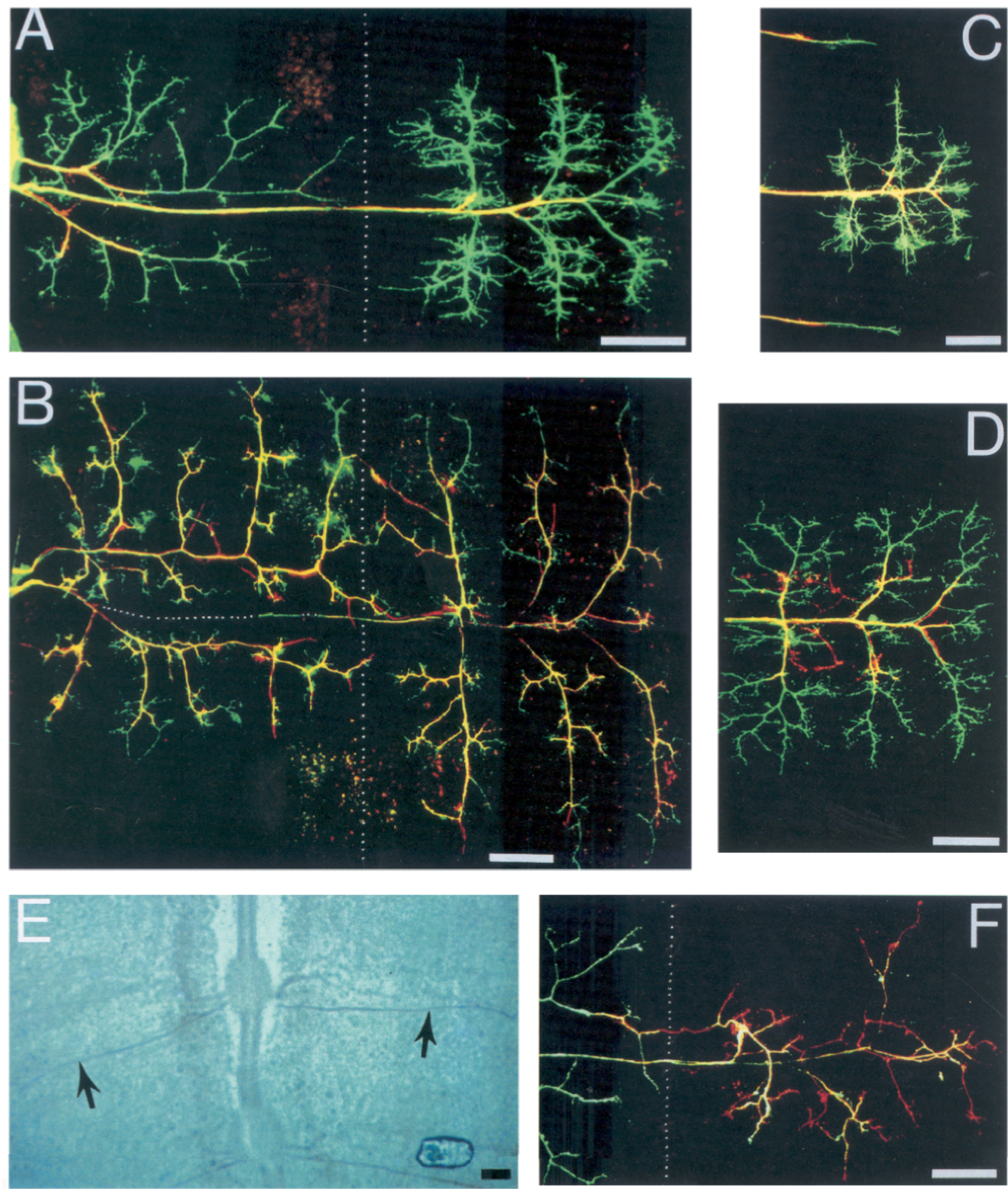

Figure 2. $A-D$, The terminal fields of the $\mathrm{P}_{\mathrm{D}}, \mathrm{AP}$, and $\mathrm{T}_{\mathrm{D}}$ neurons coincide in the dorsal germinal plate. $A$ and $B$ show double staining of the peripheral projections of two $\mathrm{P}$ cells $\left[\mathrm{DiO}\right.$, in green; the dorsal $\left(\mathrm{P}_{\mathrm{D}}\right)$ on the right and the ventral $\left(\mathrm{P}_{\mathrm{v}}\right)$ on the left of the dotted line $]$ and the later developing AP cell (DiI, red). Overlap of cells is indicated by yellow. The vertical dotted lines indicate the eventual lateral midline (see Fig. 1). $A$, The $\mathrm{P}_{\mathrm{D}}, \mathrm{P}_{\mathrm{v}}$, and AP cells at E10. B. The same cells at E12-13. The AP cell follows the branches of the $\mathrm{P}_{\mathrm{D}}$ cell up to the fourth order, thus forming a terminal field that is almost congruent with that of the $\mathrm{P}_{\mathrm{D}}$ cell in the dorsal germinal plate (on the right side of the dotted lines). The AP cell also followed the $\mathrm{P}_{\mathrm{v}}$ cell's branches in the ventral and lateral germinal plates. Part of the DP nerves dips out of the plane of focus, where the axons are indicated by dotted lines. $C$, The $\mathrm{P}_{\mathrm{D}}$ and $\mathrm{T}_{\mathrm{D}}$ cells at E10. The morphology of the $\mathrm{T}_{\mathrm{D}}$ cell is very similar to the $\mathrm{P}_{\mathrm{D}}$ cell except that it developed later. The terminal fields of the $\mathrm{T}_{\mathrm{D}}$ and $\mathrm{P}_{\mathrm{D}}$ cells will also become coincident up to the fourth-order branches at E12-13 (not shown). $D$, The $\mathrm{P}_{\mathrm{D}}$ and Retzius cells at E11. Note that some branches of the Retzius cell follow the $\mathrm{P}_{\mathrm{D}}$ 's branches, whereas others do not. Therefore, some later developing cells, but not all, use the $\mathrm{P}_{\mathrm{D}}$ neuron as templates and have similar terminal fields in the dorsal germinal plate. $E$, The formation of the DP nerve does not require the $\mathrm{P}_{\mathrm{D}}$ cell. The DP nerves were stained with antibody to acetylated-tubulin $6 \mathrm{~d}$ after ablation of the $\mathrm{P}_{\mathrm{D}}$ neuron 

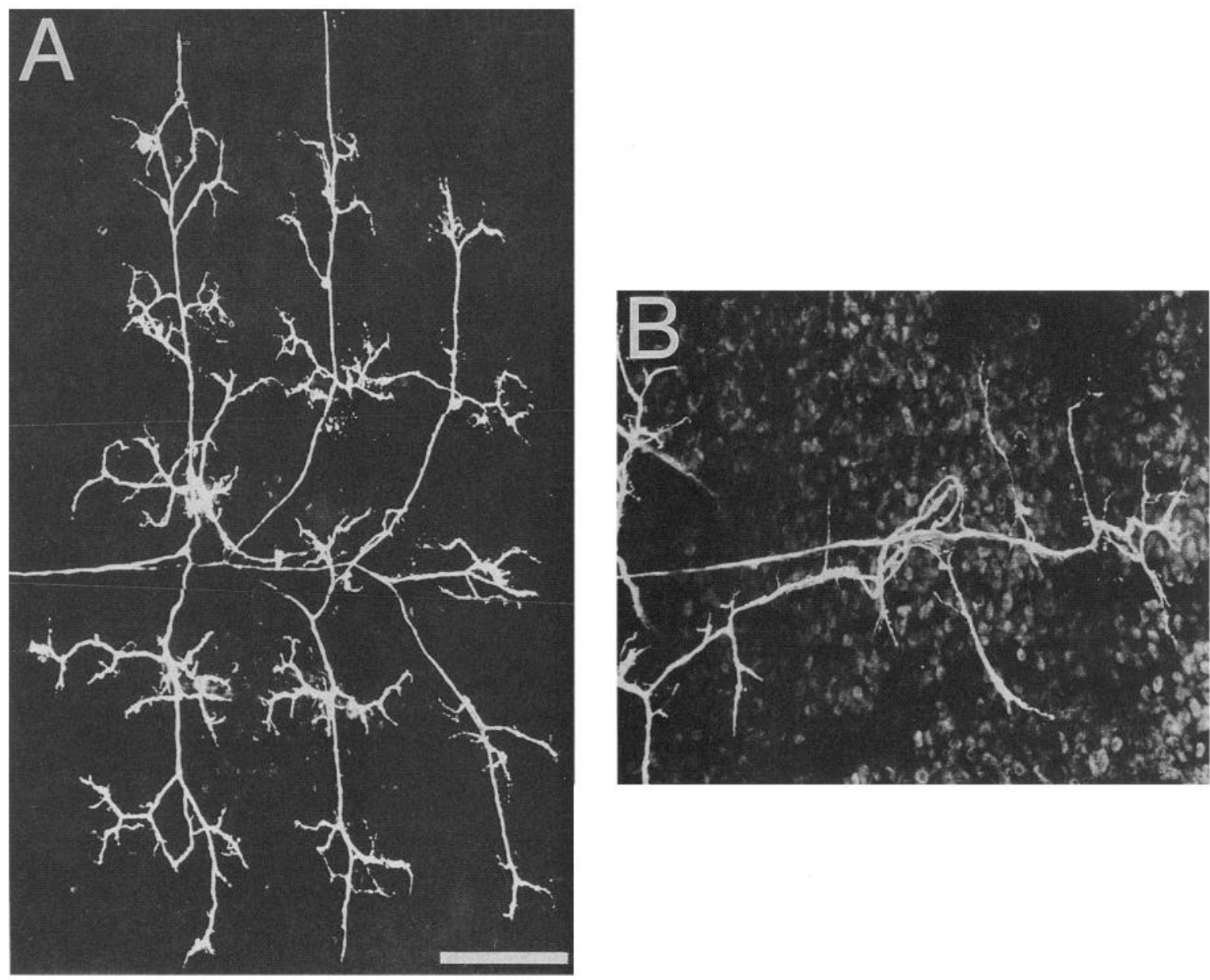

Figure 3. Outgrowth of the AP cell in the dorsal germinal plate requires the $\mathrm{P}_{\mathrm{D}}$ pioneer. $A$, The morphology of a control AP cell at E13. B, Abnormal outgrowth of the AP cell in the dorsal germinal plate at E13 after ablation of the $P_{D}$ neuron at E8. In the absence of the pioneer $P_{D}$ cell, the AP cell always showed significantly reduced axonal outgrowth and dramatically abnormal peripheral branching. Scale bar, $100 \mu \mathrm{m}$.

The AP, $T_{D}$, and $A E$ neurons use the $P_{D}$ neuron arbor as a template in establishing their own terminal arborizations, but not for initial outgrowth to the target region

To reveal possible effects of ablating the $\mathrm{P}_{\mathrm{D}}$ cell on the branching pattern of the follower neurons, individual cells were stained with DiI to examine their ability to travel to the dorsal germinal plate and establish normal arbors after the ablation of the local $P_{D}$ neuron. In the case of AP neurons, $P_{D}$ cells were ablated either at E7 $(n=27)$ or E8 $(n=36)$ and the AP cells were stained with DiI at E13. In all cases, the AP cell on the experimental side had significantly reduced growth and a very abnormal branching pattern (Fig. $3 B$ ) compared to the control AP cell on the opposite side (Fig. $3 A$ ). In contrast, the ventral arbor of the AP cell, presumably generated using the ventral $\mathrm{P}\left(\mathrm{P}_{\mathrm{V}}\right)$ neuron as a template, appeared to be unaffected (not shown).

Similar findings were obtained when the peripheral arbors of the $T_{D}$ and annulus erector (AE) neurons were examined after $P_{D}$ cell ablation. Five days after ablating $P_{D}$ cells at $E 8, T_{D}$ cells on the experimental side showed abnormal branching patterns and less outgrowth ( $n=12$ of 12). When the T $\mathrm{T}_{\mathrm{D}}$ and AP cells were both stained with different dyes in the same preparation, although their arbors overlapped extensively, the $T_{D}$ cell was always found to have more branches than the AP cell in the dorsal region (Fig. $2 F ; n=3$ ). It is not known whether they both followed another cell when the $\mathrm{P}_{\mathrm{D}}$ was killed, or whether the AP cell followed the $T_{D}$ cell. In addition, we found that the dorsal posterior branch of the AE motor neuron, which has an arbor similar to that of the AP, also had abnormal branching and reduced outgrowth ( $n=3$ of 3 ; not shown).

The particular branching patterns of the follower cells on the experimental side varied from one preparation to another, but were, nevertheless, quite distinct from controls. These results suggest that the establishment of correct terminal arborizations for the $\mathrm{AP}, \mathrm{T}_{\mathrm{D}}$, and $\mathrm{AE}$ neurons in dorsal skin required the presence of the $P_{D}$ cell.

Ablation of the $P_{D}$ neuron might affect the follower cells as

at E7. No differences between the DP nerves (arrows) in the experimental side (left) and the control side (right) were found. $F$, The abnormal growth of the $T_{D}$ and AP cells in the absence of the $P_{D}$ cell. Five days after ablation of the $P_{D}$ cell at E8, the $T_{D}($ red $)$ and AP cells $($ green $)$ grow along similar paths in the dorsal germinal plate, though the $T_{D}$ has additional erratic growth. The controls for both cells, not shown here, were normal and for the AP cell, similar to the one in $B$. The dorsal germinal plate is on the right side of the dotted line. Scale bars, $100 \mu \mathrm{m}$. 

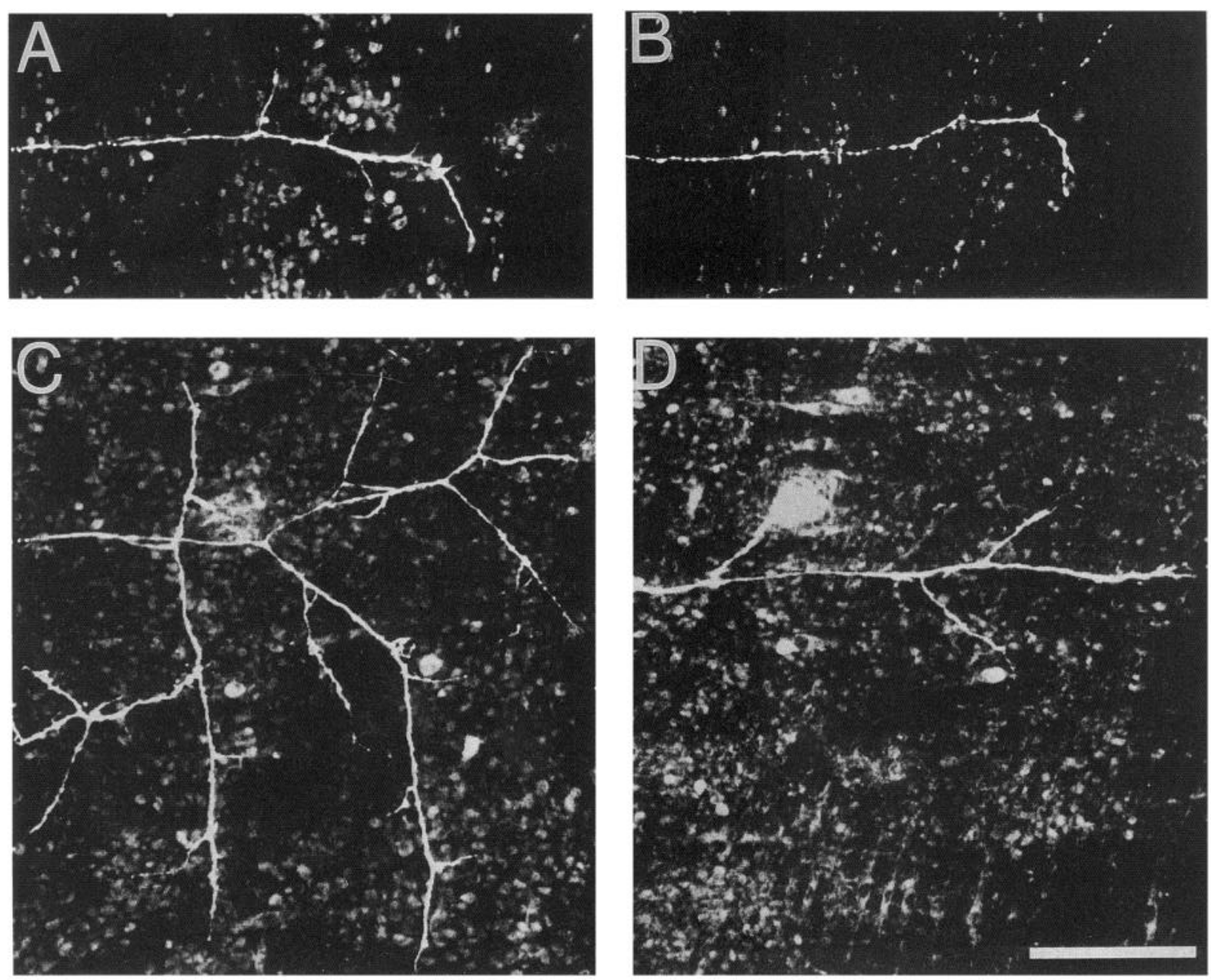

Figure 4. The initial outgrowth of AP cells is not dependent on the $\mathrm{P}_{\mathrm{D}}$ cell. A, A control AP cell, on the opposite side of the ganglion as the experimental cell in $B . B$, The experimental AP cell $2 \mathrm{~d}$ after ablation of the $\mathrm{P}_{\mathrm{D}}$ neuron at E8. It reached the dorsal germinal plate and started to branch, there being no obvious effect of the ablation. $C$, A control AP cell, contralateral to the experimental AP of $D$. $D$, The experimental AP neuron in the dorsal plate, $3 \mathrm{~d}$ after ablation of the $\mathrm{P}_{\mathrm{D}}$ cell. Its outgrowth was significantly impaired at this stage. Scale bar, $100 \mu \mathrm{m}$.

their axons first grew to the periphery or, alternatively, influenced their growth only after reaching the dorsal germinal plate. To distinguish between these possibilities, the initial outgrowth of AP neurons was examined in the absence of the $P_{D}$ cell. We found that after $\mathrm{P}_{\mathrm{D}}$ ablation at E7 $(n=6)$ or E8 $(n=6)$, the dorsal posterior branch of the AP cell still reached the dorsal germinal plate at E10 and was similar to controls (compare Fig. $4 A, B)$. Growth of the AP cell started to deviate from normal at E11, displaying less frequent and abnormal branching (compare Fig. $4 C, D ; n=4)$.

To test whether minor projections from $\mathrm{P}_{\mathrm{D}}$ cells in adjacent ganglia can guide AP axons to dorsal territory when the consegmental $\mathrm{P}_{\mathrm{D}}$ is missing, we ablated $\mathrm{P}_{\mathrm{D}}$ cells in three consecutive ganglia at E7. Three days later, the dorsal posterior branch of the AP cell in the middle ganglion was found to grow directly to or close to the dorsal region ( $n=4$ of 4 ; not shown). These results suggest that neither major nor minor branches of $P_{D}$ cells are necessary for the AP cells to initiate outgrowth or to grow to and reach dorsal territory.

\section{$P_{D}$ cell arbors are sufficient for guiding AP cells in} establishing their normal terminal fields

Although the experiments described above showed the $P_{D}$ cell to be necessary for the proper formation of AP cell terminal fields, it remained to be determined whether it was also sufficient. To prove sufficiency required our causing the $P_{D}$ neuron to grow where it normally does not, to see if the AP cell would follow novel $P_{D}$ cell arbors. To achieve this, first one $P_{D}$ neuron was killed at E8, thereby eliminating guidance from its major branch in the experimental ganglion (diagrammed in Fig. $5 B$, right; the contralateral $\mathrm{P}_{\mathrm{D}}$ neuron was also deleted, as an opposite-side control; Fig. 5A, left). We then used a technique described in the preceding companion article (Gan and Macagno, 1995 ) that induces the neighboring $P_{D}$ cell's minor projection to overgrow in the experimental segment, the cutting of its major projection. With this experimental scheme, we then tested whether the "overinduced" minor branch of the adjacent $P_{D}$ cell $\left(\mathrm{P}_{\mathrm{D}}^{\prime}\right)$ could, by growing within the vacated territory of the ablated $\mathrm{P}_{\mathrm{D}}$ neuron, be sufficient to guide the AP cell's major axon.

Four days after the operations, the control AP neuron had a restricted terminal field in the dorsal body wall and little outgrowth, as observed before. On the experimental side, however, the arbor of the AP cell had grown much larger than the control ( $n=10$ of 10 ), though the precise branching patterns of the AP cell varied somewhat from case to case. Figure 6 shows, in the dorsal germinal plate, the projections of the AP cells in the experimental ganglion (DiI, in red) and the minor and part of the 


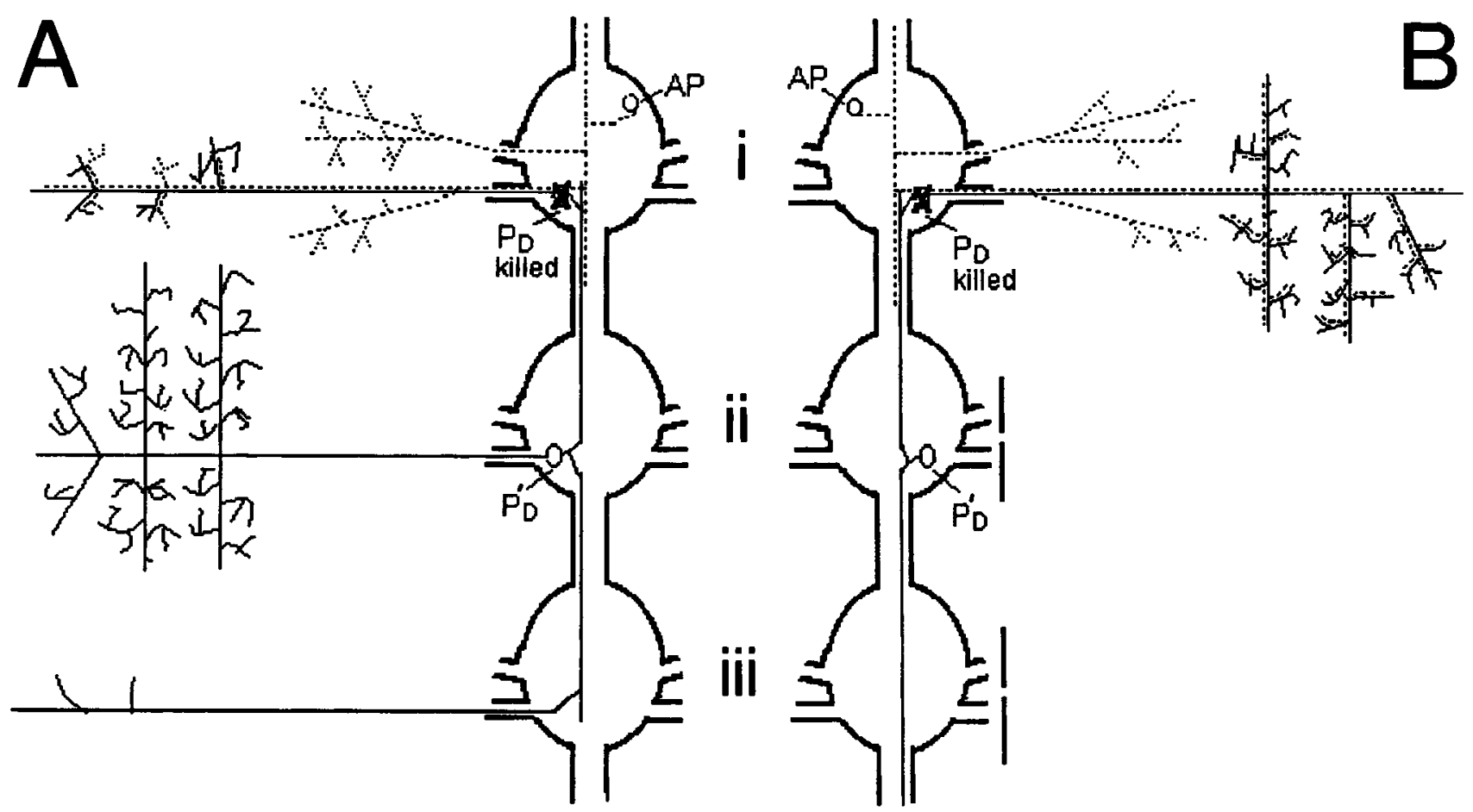

Figure 5. The experimental scheme to test whether the $\mathrm{P}_{\mathrm{D}}$ cell is sufficient to guide outgrowth of the AP cell, the control being $A$ and the experiment being $B$. Two $\mathrm{P}_{\mathrm{D}}$ cells in ganglion $(i)$ were first ablated. The roots of the next two adjacent ganglia (ii) and (iii) on the experimental side were then cut with a sharp pin so that the $\mathrm{P}^{\prime}{ }_{D}$ cell in ganglion $(I I)$ was left with its minor projection in segment $(i) B$, The operations were done at E8, when the major and the minor projections of the $\mathrm{P}^{\prime}{ }_{D}$ cell have just reached the margin of the germinal plate and the major one is about to form its first-order branches. At later stages, the two $\mathrm{P}^{\prime}{ }_{D}$ cells in ganglion $(i i)$ and the two AP cells in ganglion (i) were stained with different dyes to examine their arbors in segment $(i)$. The $\mathrm{P}^{\prime}{ }_{\mathrm{D}}$ and AP cells with projections to the left germinal plate were used as controls $(A)$.

major projections of the $\mathrm{P}^{\prime}{ }_{\mathrm{D}}$ cells in the adjacent, more posterior ganglion (DiO, in green). On the control side, some branches of the AP cell followed the minor projection of the adjacent $\mathrm{P}^{\prime}{ }_{\mathrm{D}}$ cell, but some branches did not (Fig. 6A). On the experimental side, there was clearly much more outgrowth of the neighboring $\mathrm{P}^{\prime}{ }_{\mathrm{D}}$ cell and the local AP cell than on the control side (Fig. $6 B$ ). It appeared, $4 \mathrm{~d}$ after the operation, that the branches of the AP cell followed the novel $\mathrm{P}_{\mathrm{D}}^{\prime}$ projections in the dorsal germinal plate. Thus, the $\mathrm{P}_{D}^{\prime}$ cell appears to be sufficient as a guide for the AP cell to establish its arbor.

In Figure 6, $C$ and $D$ show the outgrowth of the AP cell (red) and the minor projection of the adjacent $\mathrm{P}_{\mathrm{D}}^{\prime}$ cell (green) $2 \mathrm{~d}$ later, $6 \mathrm{~d}$ after the operation. The $\mathrm{P}_{\mathrm{D}}^{\prime}$ cell's arbor has grown asymmetrically due to inhibition by the $P_{D}$ cell in the next, more anterior ganglion (see preceding companion article, Gan and Macagno, 1995). Concomitantly, the AP cell also generated an asymmetric arbor by following the minor projection of the neighboring $\mathrm{P}_{n}^{\prime}$ cell, up to the fourth order. The minor projection of the $\mathrm{P}_{\mathrm{D}}^{\prime}$ cell and the projection of the AP cell both had significant increases in outgrowth on the experimental side during the additional $2 \mathrm{~d}$, but they did not on the control side. Interestingly, sometimes the AP cell can also follow the major projection of the adjacent $\mathrm{P}_{\mathrm{D}}^{\prime}$ cell (Fig. $6 A, C$ ).

\section{Discussion}

The data presented in this report show that the AP motor neuron and the $T_{D}$ sensory neuron depend on a putative pioneering sensory cell (the $P_{D}$ cell) for the establishment of their terminal arbors. Our observations also show that another motor neuron, the AE cell, behaves very much as the AP cell does. The follower cells duplicate the arbors of the $P_{D}$ cell in the body wall, up to the fourth-order branches, though they eventually diverge near the superficial layers. The $P_{D}$ cell is not, however, required for the initial directional growth toward a particular region of the periphery.

\section{Follower outgrowth is affected specifically by $P_{D}$ ablation}

The abnomal outgrowth of the AP and $T_{D}$ cells in the dorsal germinal plate after ablation of the $P_{D}$ cell was clearly not due to nonspecific effects of the experimental procedures. For example, there was no discernable change in the ventral branching pattern of the AP cell after ablation of the $P_{D}$, although the effect on its dorsal branching pattern was severe. Moreover, normal pathfinding by the minor projection of the adjacent $P_{D}$ cell and the rescue of AP cell outgrowth by the adjacent $P_{D}$ cell's induced growth suggest that the ablation did not disturb the local cues presumably used by the $P_{D}$ cells for guidance. Thus, the reduced and abnormal outgrowth of the AP and $T_{D}$ neurons in the absence of the $P_{D}$ cell must have arisen specifically from the loss of the guidance cues to which the $P_{D}$ cell normally provides access in the dorsal region.

\section{What governs the initial outgrowth of later-developing neurons?}

Our results indicate that the AP and other follower cells are apparently able to recognize guidance cues to grow to the dorsal target area without the $P_{D}$ cell. However, it is not clear what controls the correct initial outgrowth of these follower cells in the absence of the $P_{D}$ cell. One possibility is that the cues used by the $P_{D}$ cell may still be available at the time when the AP, $T_{D}$, and $A E$ cells grow to the dorsal germinal plate and may be directly recognized by these later developing neurons. Alterna- 

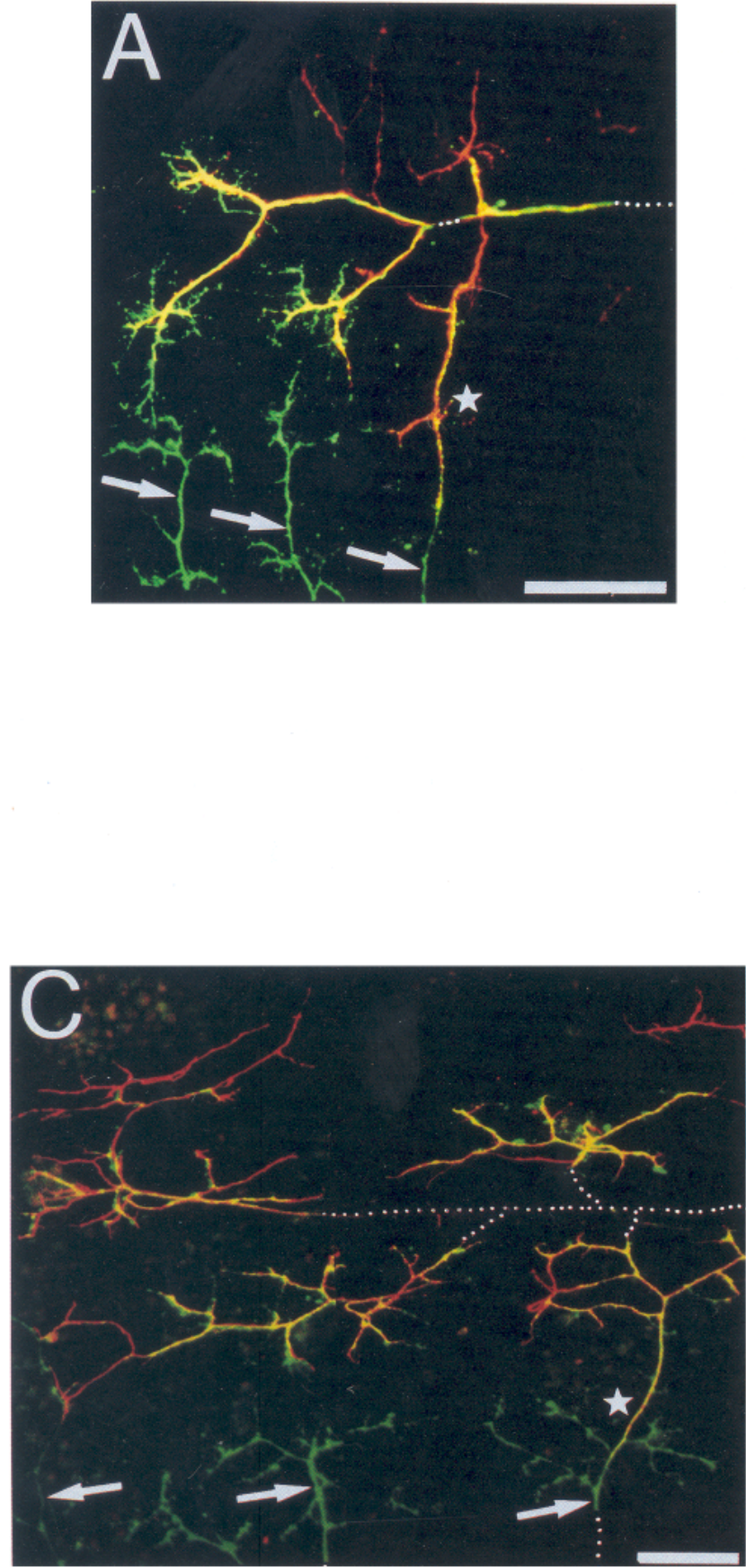
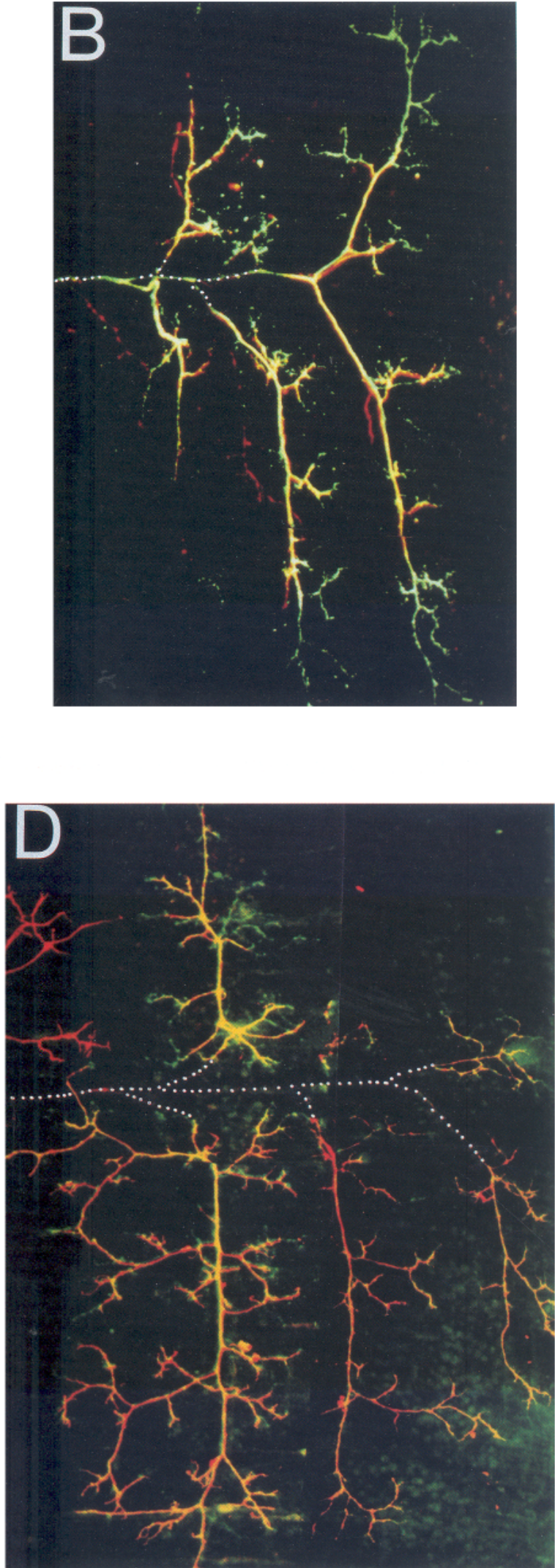

Figure 6. The $\mathrm{P}_{\mathrm{D}}$ cells are sufficient to guide the AP cells to establish normal terminal fields. In all the panels, the AP cells in ganglion (i) were stained with DiI (in red) and the $\mathrm{P}^{\prime}{ }_{\mathrm{D}}$ cells in ganglion (ii) with $\mathrm{DiO}$ (in green) (see experimental scheme illustrated in Fig. 5). Branches of the $\mathrm{P}^{\prime}{ }_{\mathrm{D}}$ and AP cells outside the volume imaged with the confocal microscope are depicted with dotted lines in all the panels. Dorsal is to the left in $A$ and $C$, to the right in $B$ and $D$. A, Four days after ablation, the AP cell on the control side of segment $(i)$ had limited outgrowth, as expected. Some branches of the AP cell followed the branches of the minor projection of the $\mathrm{P}^{\prime}{ }_{\mathrm{D}}$ cell, whereas others did not. Arrows at bottom indicate the 
tively, the later developing neurons may simply fasciculate with other early axons to reach the dorsal germinal plate. At present, we are unable to distinguish between these two possibilities.

Studies in many other systems have shown that some pioneer neurons do participate in guiding the early phases of axonal outgrowth of later developing neurons, whereas others do not (Macagno, 1978; Keshishian and Bentley, 1983; Raper et al., 1984; Kuwada, 1986; Eisen et al., 1989; Klose and Bentley, 1989; Tix et al., 1989; Ghosh et al., 1990; Pike et al., 1992; McConnell et al., 1994). One interesting question is why in some systems, but not in others, later developing neurons appear to recognize the same guidance cues as do the pioneer neurons. As pointed out by Bentley and Keshishian (1982), pioneers and later developing neurons may have the same ability to read simple environmental cues. However, pioneers usually navigate at a time when the distances between neurons and their targets are short and environments are relatively uncomplicated. Presumably, later developing neurons in some systems would fail to find the appropriate pathways without the pioneer because the environment they grow in may have become more complex, guidance cues might disappear with time, and/or distances to cues (e.g., guidepost cells) might increase beyond the ability of followers to sense. Hence, whether or not the later developing neuron can grow properly in the absence of the pioneer may depend on how complex the environment becomes by the time these followers navigate through it.

\section{The role of the pioneer in establishing terminal fields}

Our data, that the AP and $\mathrm{T}_{\mathrm{I}}$ neurons can grow correctly to but can't branch appropriately in the target area without the $P_{1}$, cell, are reminiscent of recent studies of the role of pioneering subplate neurons in the guidance of descending axons from cerebral cortex in cats and ferrets (McConnell et al., 1994). After ablation of subplate neurons, the later developing subcortical projections from cortical neurons of Layer VI can still reach their target, the lateral geniculate nucleus (LGN), but fail to invade it afterwards. It is not known how the subplate neurons facilitate the invasion of the subcortical projections into the LGN.

In our system, interactions between the $P_{1}$ and the follower neurons play a critical role in the growth of the followers within the dorsal germinal plate. It is not clear whether the AP and $T_{D}$ cells lack mechanisms to recognize the same guidance cues recognized by the $P_{D}$ cell or, alternatively, whether the cues used by the $P_{1}$ cell to form its terminal field become unavailable by the time that the AP and $T_{D}$ cells arrive at the dorsal area. Although the AP and $T_{1}$ cell may grow in the dorsal area by simply fasciculating with the preexisting branches of the $P_{D}$ cell, our observation that the outgrowth of the $A P$ and $T_{D}$ cell is promoted in the presence of the $P_{D}$ cell also suggests other possibilities. For example, the $P_{D}$ cell might act as a substrate that promotes the growth of the follower cells in the dorsal region. The enhanced outgrowth of the followers may then enable these followers to recognize guidance cues themselves. In this model, ablation of the $P_{D}$ neurons results in the much slower growth rate of the $A P$ and $T_{D}$ cell in the expanding germinal plate and, secondarily, in the inability of these cells to recognize the existing paths to their normal targets.

\section{The role of filopodia in the detection of guidance cues}

The major projection of the $\mathrm{P}_{\mathrm{D}}$ cell produces many filopodia along its shaft and at the growth cones, which then disappear gradually. In contrast, the AP and $T_{D}$ neurons have few or no filopodia. Could their lack of filopodia account for their inability to navigate correctly in dorsal territory in the absence of the pioneer? Indeed, studies in other systems indicate that pioneer neurons often have more complex growth cones than later developing neurons (LoPresti et al., 1973; Nordlander, 1987; Kim et al., 1991; Yaginuma et al., 1991), and filopodia have been shown to be important for growth cone steering both in vitro and in situ (Letourneau, 1975; O'Connor et al., 1990; Myers and Bastiani, 1993). In fact, disruption of filopodia by cytochalasin treatment results in abnormal pathfinding by the Til neuron in grasshoppers (Bentley and Toroian-Raymond, 1986) and by retinal growth cones in the Xenopus brain (Chien et al., 1993). It is not known whether AP and $T_{\mathrm{D}}$ cells lack an intrinsic ability to produce many filopodia, or whether their environments are merely not conducive to such formation. However, it is worth noting that $\mathrm{P}_{\mathrm{D}}$ neuron branches lack many filopodia when they overlap with branches of a segmental homolog, and recover them when that homolog is ablated (Gan and Macagno, 1995). In the case of the AP and $T_{D}$ neurons, however, ablation of the $P_{D}$ cell does not result in a very significant increase in filopodia extension by these cells, which correlates with their inability to generate a normal arbor.

Based on our observations as well as those of others (Kramer and Kuwada, 1983; Kuwada and Kramer, 1983), we propose that $P_{D}$ neurons have the capacity to recognize two kinds of substrate cues, those that allow their growth cones to navigate toward dorsal regions and those that allow them to generate stereotypic arbors in the target area. In contrast, the growth cones of later developing neurons are capable of recognizing initial cues, but once they reach the target, rely on the $P_{D}$ arbor for the generation of their terminal fields. This strategy provides a simple mechanism by which neurons with different functions can efficiently innervate common territory.

\section{References}

Ball EE, Ho RK, Goodman CS (1985) Development of neuromuscular specificity in the grasshopper embryo: guidance of motoneuron growth cones by muscle pioneers. J Neurosci 5:1808-1819.

Bate CM (1976) Pioneer neurones in an insect embryo. Nature 260: $54-56$.

Bentley D, Keshishian H (1982) Pathfinding by peripheral pioneer neurons in grasshoppers. Science 218:1082-1088.

Bentley D, Toroian-Raymond A (1986) Disoriented pathfinding by pioneer neurone growth cone deprived of filopodia by cytochalasin treatment. Nature 323:712-715

three anterior primary branches of the $\mathrm{P}_{1}^{\prime}$ cell. Note that a branch of the AP cell has jumped to and is growing along one of these (star). B, Four days after ablation, the minor projection of the $\mathbf{P}^{\prime}{ }_{10}$ cell on the experimental side has been induced to grow extensively in segment $(i)$. Most branches of the AP cell in the dorsal germinal plate followed the minor projection of the $\mathrm{P}^{\prime}{ }_{\mathrm{D}}$ cell, up to the fourth order. There is considerable greater outgrowth of the AP cell on the experimental side than on the control side. $C$ and $D$. The control and experimental sides, $6 \mathrm{~d}$ after ablation. Clearly, there was extensive outgrowth of the AP cell, which followed the induced minor projection of adjacent $\mathbf{P}^{\prime}{ }_{D}$ cell, on the experimental side. Arrows in $C$ indicate the branches of the major projections of the $\mathrm{P}^{\prime}{ }_{D}$ cells. A branch of the AP cell in $C$ appears to follow a branch of the major projection of the $\mathrm{P}^{\prime}{ }_{\mathrm{D}}$ cell (star), as in $A$. Scale bars, $100 \mu \mathrm{m}$ (bar in $A$ also for $B$; bar in $C$ also for $D$ ). 
Blackshaw SE (1981) Morphology and distribution of touch cell terminals in the skin of the leech. J Physiol (Lond) 320:219-228.

Chien C-B, Rosenthal DE, Harris WA, Holt CE (1993) Navigational error made by growth cones without filopodia in the embryonic Xenopus brain. Neuron 11:237-251.

Eisen JS, Pike SH, Debu B (1989) The growth cones of identified motoneurons in embryonic zebrafish select appropriate pathways in the absence of specific cellular interactions. Neuron 2:1097-1104.

Gan WB, Macagno ER (1995) Interactions between segmental homologs and between isoneuronal branches guide the formation of sensory terminal fields. J Neurosci 15:3243-3253.

Gan WB, Wolszon LR, Macagno ER (1993) The development of the peripheral terminal fields of AP and dorsal $\mathrm{T}$ neurons depends on pioneer dorsal P neurons. Soc Neurosci Abstr 19:1085.

Gao WQ, Macagno ER (1987) Extension and retraction of axonal projections by some developing neurons in the leech depends upon the existence of neighboring homologues. II. The AP and AE cells. J Neurobiol 18:295-313.

Ghosh A, Antonini A, McConnell SK, Shatz CJ (1990) Requirement for subplate neurons in the formation of thalamocortical connections. Nature 347:179-181.

Goodman CS, Shatz CJ (1993) Developmental mechanisms that generate precise patterns of neuronal connectivity. Cell 72:/Neuron [Supp1] 10:77-98.

Goodman CS, Bastiani MJ, Doe CQ, du Lac S, Helfand SL, Kuwada JY, Thomas JB (1984) Cell recognition during neuronal development. Science 225:1271-1279.

Halpern ME, Chiba A, Johansen J, Keshishian H (1991) Growth cone behavior underlying the development of stereotypic synaptic connections in Drosophila embryos. J Neurosci 11:3227-3238.

Keshishian H, Bentley D (1983) Embryogenesis of peripheral nerve pathways in grasshopper legs. III. Development without pioneer neurons. Dev Biol 96:116-124.

Kim GJ, Shatz CJ, McConnell SK (1991) Morphology of pioneer and follower growth cones in the developing cerebral cortex. J Neurobiol 22:629-642.

Klose M, Bentley D (1989) Transient pioneer neurons are essential for formation of an embryonic peripheral nerve. Science 245:982-984.

Kramer AP, Kuwada JY (1983) Formation of the receptive fields of leech mechanosensory neurons during embryonic development. J Neurosci 12:2474-2486.

Kuwada JY (1985) Pioneering and pathfinding by an identified neuron in the embryonic leech. J Embryol Exp Morphol 86:155-167.

Kuwada JY (1986) Cell recognition by neuronal growth cones in a simple vertebrate embryo. Science 233:740-746.

Kuwada JY, Kramer AP (1983) Embryonic development of the leech nervous system: primary axon outgrowth of identified neurons. J Neurosci 10:2098-2111.

Landmesser LT, Dahm L, Tang J, Rutishauser U (1990) Polysialic acid as a regulator of intramuscular nerve branching during embryonic development. Neuron 4:655-667.

Letourneau PC (1975) Cell-to-substratum adhesion and guidance of axonal elongation. Dev Biol 44:92-101.

LoPresti V, Macagno ER, Levinthal C (1973) Structure and development of neuronal connections in isogenic organisms: cellular interactions in the development of the optic lamina of Daphnia. Proc Natl Acad Sci USA 70:433-437.

Macagno ER (1978) Mechanism for the formation of synaptic projections in the arthropod visual system. Nature 275:318-320.

McConnell SK, Ghosh A, Shatz CJ (1994) Subplate pioneers and the formation of descending connections from cerebral cortex. J Neurosci 4:1892-1097.

Myers PZ, Bastiani MJ (1993) Growth cone dynamics during the migration of an identified commissural growth cone. J Neurosci 13:127143.

Nordlander R (1987) Axonal growth cones in the developing amphibian spinal cord. J Comp Neurol 263:485-496.

O'Connor TP, Duerr JS, Bentley D (1990) Pioneer growth cone steering decisions mediated by single filopodia contacts in situ. J Neurosci 10:3935-3946.

Pike SH, Melancon EF, Eisen JS (1992) Pathfinding by zebrafish motoneurons in the absence of normal pioneer axons. Development 114 $825-831$

Raper JA, Bastiani MJ, Goodman CS (1983) Pathfinding by neuronal growth cones in grasshopper embryos. II. Selective fasciculation onto specific axonal pathways. J Neurosci 3:31-41.

Raper JA, Bastiani MJ, Goodman CS (1984) Pathfinding by neuronal growth cones in grasshopper embryos. IV. The effect of ablating the $A$ and $P$ axons upon the behavior of the $G$ growth cone. J Neurosci 4:2329-2345.

Sink II, Whitington PM (1991) Pathfinding in the central nervous system and periphery by identified embryonic motor axons. Development 112:307-316.

Tix S, Bate M, Technau GM (1989) Pre-existing neuronal pathways in the leg imaginal discs of Drosophila. Development 107:855-862.

Westerfield M, McMurray JV, Eisen JS (1986) Identified motoneurons and their innervation of axial muscles in the zebrafish. $\mathbf{J}$ Neurosci $6: 2267-2277$

Yaginuma H. Homma S, Kunzi R, Oppenheim RW (1991) Pathfinding by growth cones of commissural interneurons in the chick embryo spinal cord: a light and electron microscopic study. J Comp Neurol 304:78-102. 